\title{
Was the Conservative Majority Predictable?
}

\author{
by
}

Jeffrey S. Rosenthal*

(May 11, 2011; slightly revised, June 27, 2011)

(Accepted for publication in the Canadian Journal of Statistics.)

\begin{abstract}
Canada's 41 $41^{\text {st }}$ national general election saw the Conservative Party increase its seat count from 143 to 166, thus giving it a majority of the national parliament's 308 seats. By contrast, nearly all of the pre-election seat count forecasts predicted a Conservative minority only. We examine the extent to which simple statistical models could or could not have predicted the Conservative majority prior to the election. We conclude that, by using data from the previous (2008) election appropriately, the Conservative majority should have been anticipated as the most likely outcome.
\end{abstract}

MSC 2010 subject classification: $62 \mathrm{P} 25$.

\section{Introduction.}

Canada's $41^{\text {st }}$ national general election was held on May 2, 2011. Five major political parties competed for votes: the Conservative Party of Canada, the Liberal Party of Canada, the New Democratic Party (NDP), the Bloc Québecois (in Quebec only), and the Green Party of Canada.

Public opinion polls at the start of the election campaign predicted a result very similar to that of the previous national election of 2008, in which the Conservative Party of Canada won 143 of the 308 seats available. About two weeks before the election, polls indicated a sudden and unexpected surge in support for the third-place New Democratic Party (NDP), while the support levels of the ruling Conservative Party of Canada remained approximately constant. These polls were widely studied and debated.

\footnotetext{
*Department of Statistics, University of Toronto, Toronto, Ontario, Canada M5S 3G3. Email: jeff@math.toronto.edu. Web: http://probability.ca/jeff/ Supported in part by NSERC of Canada.
} 
Of particular interest was whether or not the Conservatives would win a majority of the 308 seats, thus allowing them to pass legislation without the cooperation of any other political party. In the days preceding the election, a clear consensus emerged among pollsters, forecasters, columnists, and even Conservative Party officials, that the Conservatives would fall short of winning a majority (see Section 3). So, it was considered quite surprising when, on election night, the Conservatives saw their seat count increase from 143 to 166, a clear majority.

In this paper, we consider the extent to which this result should or should not have been surprising, i.e. the extent to which the Conservative majority could or could not be predicted on the basis of the pre-election polling data available.

\section{Pre-Election Polls.}

Numerous pre-election public opinion polls were published throughout the election campaign. All showed essentially the same story: popular support for the various political parties remained very close to that of the 2008 election until approximately two weeks before the election, at which point the NDP's popularity increased dramatically (primarily at the expense of the Liberals and the Bloc) while the Conservative support remained essentially constant. The poll results then remained virtually constant for the final five days of the campaign. This is all nicely illustrated in e.g. the following graph of daily poll averages taken from [17].

\section{CANADA - Daily Poll Averages}

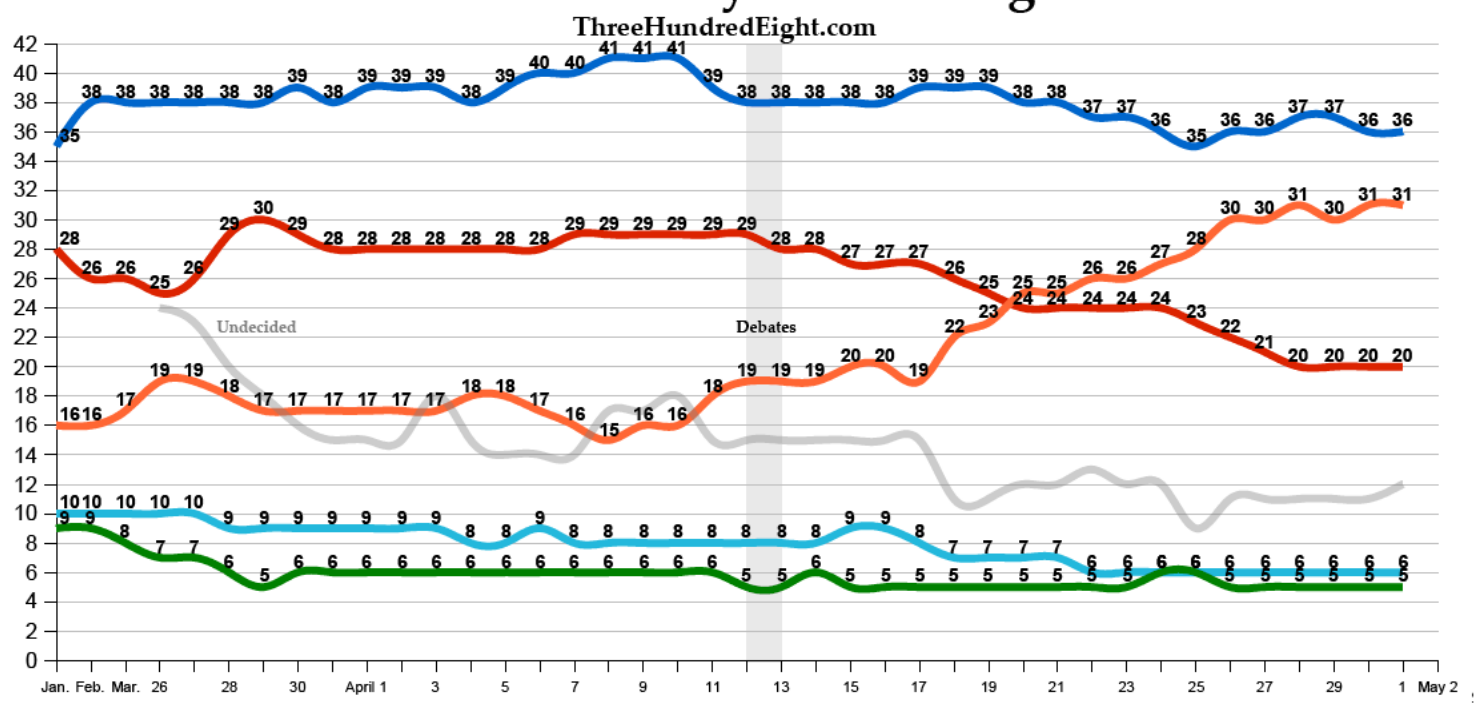

Figure 1: Opinion poll trends during the 2011 election campaign. 
The proliferation of pre-election polls made it challenging to even keep track of them all. We have attempted here to identify (with help from such monitoring web sites as [21], [17], and [39]) the final pre-election polls from each of the major national polling companies, as follows:

\begin{tabular}{|c|c|c|}
\hline Polling Company & publication date & sample size \\
\hline Forum [14] & May 1, 2011 & 3483 \\
Nanos [30] & May 1, 2011 & 1054 \\
Ekos [12] & May 1, 2011 & 3144 \\
Harris-Decima [20] & May 1, 2011 & 1035 \\
Compas [8] & May 1, 2011 & 750 \\
Angus Reid [3] & Apr 30, 2011 & 3003 \\
Ipsos [23] & Apr 29, 2011 & 1710 \\
Leger [25] & Apr 30, 2011 & 3521 \\
Abacus [1] & May 1, 2011 & 1007 \\
\hline & Total: & 18707 \\
\hline
\end{tabular}

Table 1: The nine pre-election polls used in this study.

These nine polls used somewhat different methodologies and had different sample sizes, but were generally consistent in their results. Like many Canadian national public opinion polls, they also provided a breakdown of their results into five distinct regions of Canada: the Atlantic Provinces (Newfoundland and Labrador, Prince Edward Island, New Brunswick, and Nova Scotia), Quebec, Ontario, the Prairies (Manitoba, Saskatchewan, Alberta, and the three northern territories), and British Columbia (B.C.). (Some of the polls separate out Alberta from the Prairies, in which case we re-combined them for consistency.) The average of the nine polls, by region, weighted by sample size, is as follows:

\begin{tabular}{|c|c|c|c|c|c|c|}
\hline & Canada & Atln & Que & Ont & Prair & B.C. \\
\hline Con & 35.75 & 31.60 & 14.85 & 40.11 & 57.17 & 39.96 \\
Lib & 19.57 & 25.78 & 13.90 & 26.01 & 13.37 & 15.82 \\
NDP & 31.74 & 38.39 & 41.24 & 28.29 & 23.26 & 31.49 \\
Bloc & 6.24 & 0.00 & 25.70 & 0.00 & 0.00 & 0.00 \\
Green & 4.97 & 3.50 & 3.41 & 4.94 & 5.68 & 8.06 \\
\hline
\end{tabular}

Table 2: The regional weighted averages of the final pre-election poll results. 


\section{Pre-Election Seat Count Projections.}

A major challenge is to then use these polling results to attempt to extrapolate seat counts for each party. This is difficult since each seat is awarded to the candidate with the most votes in that riding, and a party's percentage of seats is often very different from its overall percentage of votes. (For example, in the 2008 Canadian general election, the Conservatives received $37.67 \%$ of the votes but $46.4 \%$ of the seats; the Bloc received $9.98 \%$ of the votes but $15.9 \%$ of the seats; and the Greens received $6.78 \%$ of the votes but zero seats.)

Various individuals and organisations did attempt to use these polling results to extrapolate seat counts for each party. Some of these attempts were overly simplistic and did not inspire confidence. Others used more sophisticated seat projection algorithms but encountered other difficulties, e.g. the projections of [17] did not sufficiently discount early polls so they did not fully take into account the late NDP surge. In any case, only a small minority of the seat projections accurately projected the Conservative majority. For example, of the ten projections summarised by [10], only two of them (20\%) predicted a Conservative majority. Indeed, the day before the election, the president of the Forum Research polling company even stated that the most seats could plausibly be won by either the Conservatives or the NDP, and that the Liberals and NDP together might well hold a majority of the seats [31].

Even those projections which offered ranges rather than point estimates often missed the majority possibility entirely. For example, [12] predicted that the Conservatives would win "130 to 146 seats", well short of the 155 majority figure. One slight exception is that [17] provided "ceilings" for each party, which it defined (somewhat unconventionally) to be the result assuming the party's vote percentage in each region is equal to their largest regional support in any recent opinion poll. And, indeed, they found that the Conservative Party's "ceiling" was equal to 167 seats, essentially their actual seat total in the election. However, they emphasised that they were "not projecting any of these scenarios to actually take place", and that these ceilings were "not actual projections of likely outcomes", so they were presumably not meant to be taken very seriously.

The general consensus that the Conservatives would fall short of a majority was widely reported in the media. For example:

- One political science professor stated on May 1, "As things stand at the moment, the (Conservative) government is likely to end up further from a majority rather than inch closer", opining that a Conservative minority was the most likely outcome [28].

- A senior political Toronto Star columnist speculated on April 30 about what would result "if the election is, as polls suggest, inconclusive [i.e. without majority]" [5]. 
- Another newspaper columnist scoffed on April 28 that "it would take nothing short of political sleight of hand" for the Conservatives to achieve a majority [18].

- A National Post political columnist asserted on April 29 that the Conservatives "may as well shout into the wind as call for a majority" [24].

- Another columnist summarised in a more scientific way on April 29 that "averaging seat forecasts from four sources, at four points in time, reveals a narrative: Conservatives stalled shy of a 155-seat majority" [11].

- A Winnipeg Free Press columnist lamented on April 30 that "What initially looked like a potential majority for [the Conservatives] has begun to look like another minority" [29].

- Even David Frum, the Canadian right-wing columnist and one time George W. Bush speech-writer, opined in the National Post on April 30 that "Canada looks headed for a startling election outcome on May 2: An expanded Conservative government, falling short of a majority ..." [16].

- In business news, predictions of a weak Conservative election performance led to articles like "Traders jolted awake by election uncertainty; could see loonie, stock volatility" in the Winnipeg Free Press on May 1, in which a senior markets manager suggested that the latest polls "upended previous predictions that the Conservatives would get enough votes to form" even a minority government, much less a majority, and worried that he "will be busy Monday evening trading the Canadian dollar" after a weaker-thanexpected Conservative showing; the Bank of Montreal deputy chief economist provided the reassurance that he "still believes a minority [not majority] government is the most likely scenario" [15].

- Leading Canadian pollster Frank Graves declared of the Conservatives on May 1, “there's no chance they're going to get a majority" [19].

- Local reporters routinely and confidently made assertions such as "Opinion polls suggest another Conservative minority government" [32].

- From as far away as the U.K., Reuters noted on May 1 that a recent poll result "strongly suggests the election will produce another Conservative minority" [26].

- Senior Conservative Party officials themselves publicly conceded on April 29 that a majority was "almost impossible", saying "we're just not there" and "there is currently no seat matrix that gets [the Conservatives] to a majority" [4].

- Over a month after the election, a Conservative senator reminisced how "the national press did not see a [Conservative] majority government coming in the May 2 election, figuring instead the Conservatives would be leading a minority government after the election" [36]. 
Of course, there were also many articles which asserted that the election was "a nailbiter" (i.e., too close to call), or that a Conservative majority "remains plausible". However, the clear consensus among the experts and pollsters and media was that the Conservative Party would not win a majority of the 308 seats available.

This leads to the question of whether or not that majority could or should have been predicted in advance. Our interest in this question was piqued when, the day before the election, we happened to read a blog post by a journalist [9] whose riding-by-riding "farting around with numbers" led him to conclude that "the Conservative push for a majority will come down to the wire. And I think they are a little more likely to get there than not." We found his casual musings to be more convincing than the various formal seat projections available, leading us to anticipate for the first time a majority outcome. But why had this one blog post projected so accurately and convincingly when so many other seat projections had failed?

\section{A Simple Seat Projection Model.}

To further investigate this question, we next consider a simple seat projection model, to see what conclusions can be drawn from it.

Our approach is to begin in each riding with the results for each party in the previous (2008) election [13], and then adjust them based on the latest polls. Suppose that in the previous election, in a given riding, a total of $T$ votes were cast, of which $w$ were received by a given party. Suppose further that this party is currently estimated to have the regional support of a fraction $p$ of the voters, and in the last election had the corresponding support of a fraction $r$ of the voters. Then we can estimate this party's votes in the riding in the upcoming election using either a uniform voter-shift adjustment:

$$
v=w+(p-r) T
$$

or alternatively using a ratio voter adjustment:

$$
v=w p / r .
$$

(We prefer model (2) to model (1), but consider both models below; in any case the results from both models will usually be similar.) By providing such estimates for each party in a given riding, we can then estimate which party will receive the most votes in that riding (and thus win that seat). By performing similar estimates for each of the 308 ridings, we can obtain an estimated seat count for each party in the upcoming election. 
In using such a model, it is crucial to obtain good estimates of the support $p$ of each party. Ideally we would have an estimate $p$ which is specific to the riding in question. Unfortunately, such riding-by-riding polling data is rarely available. On the other hand, a single national public-support figure would be of limited value, since Canadian voting patterns vary widely by region (e.g. the Bloc has traditionally been very strong in Québec but do not run candidates in other provinces; the Conservatives are traditionally much stronger in the Prairies; the Liberals are traditionally strong in Ontario and the Atlantic provinces; etc.). So, as a compromise, we use average regional polling figures for $p$ as in Table 2 above (and corresponding regional election results for $r$ ).

We make one further adjustment. Some parties are well known to be better than others at getting their nominal supporters to actually vote for them. This is partially due to their having good "ground organisations" which allow them to organise "get out the vote" efforts, thus helping their supporters get to the polling stations on election day. It is also partially because their voters are known to be more "committed" to the party and thus more likely to bother to vote (and not change their mind). Such effects can lead certain parties to outperform their nominal polling numbers. For example, the Conservatives are well known to have a strong get-out-the-vote organisation (see e.g. [27]) and also highly committed voters (see e.g. [2]), facts which will surely work in their favour in an election.

To account for such factors, we wish to estimate each party's tendency to over-perform (or under-perform) their corresponding poll numbers. We do this by using the previous (2008) election as a guide. Specifically, we use the five most recent opinion polls prior to 2008 election (according to [21]) to obtain an average poll result (weighted by sample size) for each of the five parties. We then compare that to their actual vote percentage in the actual election, and take the corresponding difference as our estimate of their "poll over-performing effect". Our calculations are as follows:

\begin{tabular}{|c|c|c|c|c|c|c|}
\hline Company & sample size & Con & Lib & NDP & Bloc & Grn \\
\hline Ekos & 2358 & 35 & 26 & 19 & 10 & 10 \\
Nanos & 1269 & 34 & 27 & 21 & 10 & 8 \\
Harris & 1256 & 34 & 25 & 19 & 11 & 9 \\
Angus Reid & 1039 & 37 & 27 & 20 & 9 & 7 \\
Strategic & 1000 & 33 & 28 & 18 & 9 & 11 \\
\hline & weighted average & 34.65 & 26.44 & 19.39 & 9.89 & 9.15 \\
& actual election result & 37.65 & 26.26 & 18.18 & 9.98 & 6.78 \\
& over-performance (2008) & 3.00 & -0.18 & -1.17 & 0.09 & -2.37 \\
\hline
\end{tabular}

Table 3: The previous (2008) election's five final polls (from [21]) and poll average (weighted by sample size) and actual election results, leading to a corresponding estimate of each party's "poll over-performing effect". 
These over-performance values, in particular the Conservatives' large positive value (+3.00), are consistent with the the Conservatives' "demonstrated ability to get out their vote" (see e.g. [27]) and their "highest level of committed voters" (see e.g. [2]). As a further check, now that the 2011 election has passed, we can also compute each party's over-performance for that election too, as follows:

\begin{tabular}{|c|c|c|c|c|c|}
\hline & Con & Lib & NDP & Bloc & Grn \\
\hline weighted average & 35.75 & 19.57 & 31.74 & 6.24 & 4.97 \\
election result & 39.62 & 18.91 & 30.62 & 6.05 & 3.91 \\
over-performance (2011) & 3.87 & -0.66 & -1.12 & -0.19 & -1.06 \\
\hline
\end{tabular}

Table 4: The current (2011) election's average pre-election poll results (from Table 2) and actual election results, used to check each party's "poll over-performing effect".

Comparing Tables 3 and 4 shows a remarkable consistency of each party's "over-performing effect", and confirms our previous intuition that over-performing in 2008 would provide a good estimate of over-performing in 2011.

Thus, our final seat count prediction model involves forecasting the winner in each riding using the adjusted vote counts of (2) (or (1)), where $p$ is obtained from the average regional poll result from Table 2 together with the party's poll over-performing effect from Table 3. This is the model that we use below.

Remark. Of course, this seat projection model is very simplistic. It does not take into account such factors as riding incumbency, "star" local candidates, unique local issues and circumstances, riding-specific campaign strategies (such as the Green party putting most of its effort into a single B.C. riding in an effort to win its first seat, or the Conservatives concentrating their campaign resources on certain close ridings [7]), etc., all of which can impact on particular ridings above and beyond any regional trends. With sufficient "inside knowledge" of the inner workings of the electorate it may be possible to improve the model by incorporating these various additional factors. However, for purposes of this paper we do not do so, since we are interested in the extent to which the Conservative majority could have been predicted without such inside knowledge. 


\section{Results.}

We next apply various versions of our model as above, to investigate the extent to which they are able to predict the Conservative majority based on the pre-election polls. We implemented this using a C program and corresponding data files which are publicly available [35]. We consider both model (1) and (2), with or without the "poll over-performing effect" of Table 3 .

Our results are as follows:

\begin{tabular}{|c|c|c|c|c|c|}
\hline & $(1), \mathrm{N}$ & $(1), \mathrm{Y}$ & $(2), \mathrm{N}$ & $(2), \mathrm{Y}$ & actual \\
\hline Con & 147 & 157 & 148 & 160 & 166 \\
Lib & 47 & 40 & 37 & 33 & 34 \\
NDP & 109 & 104 & 111 & 103 & 103 \\
Bloc & 5 & 7 & 12 & 12 & 4 \\
Green & 0 & 0 & 0 & 0 & 1 \\
\hline
\end{tabular}

Table 5: Predicted total seat counts, by party, for either model (1) or (2), either without (N) or with (Y) the "poll over-performing effect" of Table 3. The actual results of the 2011 election are also shown.

Examining this table, we see that the choice of model (1) or (2) makes little difference (as expected). More importantly, we see that if the over-performing effect is not included, then the predicted Conservative seat count is 147 or 148, short of the 155 majority figure. On the other hand, if the over-performing effect is included, as we feel it should be, then the predicted Conservative seat count is 157 or 160, above the 155 majority figure.

On this basis, we assert that with the simple statistical model used here, and taking into account each party's over-performing effect, a Conservative majority should have been predicted with far higher confidence than was the case in the pre-election period.

For completeness, for our preferred model (i.e., model (2) with the over-performing effect), we next present the predicted seat count for each party in each region of the country, together with the actual final seat counts from the 2011 election (from [22]) for comparison:

\begin{tabular}{|c|c|c|c|c|c|c|}
\hline Region & Con & Lib & NDP & Bloc & Grn & Total \\
\hline Canada: & $160(166)$ & $33(34)$ & $103(103)$ & $12(4)$ & $0(1)$ & 308 \\
\hline Atlantic: & $14(14)$ & $9(12)$ & $9(6)$ & $0(0)$ & $0(0)$ & 32 \\
Quebec: & $7(5)$ & $3(7)$ & $53(59)$ & $12(4)$ & $0(0)$ & 75 \\
Ontario: & $68(73)$ & $16(11)$ & $22(22)$ & $0(0)$ & $0(0)$ & 106 \\
Prairies: & $49(53)$ & $3(2)$ & $7(4)$ & $0(0)$ & $0(0)$ & 59 \\
B.C.: & $22(21)$ & $2(2)$ & $12(12)$ & $0(0)$ & $0(1)$ & 36 \\
\hline
\end{tabular}


Table 6: Projected seat counts by party for the 2011 election, using our preferred model of (2) together with the over-performing effect from Table 3. Actual 2011 election seat count results are given in brackets, for comparison.

Table 6 indicates that our seat count predictions are indeed quite accurate; they slightly under-estimate the Conservative count (especially in Ontario at the expense of the Liberals), and slightly over-estimate the Bloc's performance in Quebec, but generally give quite accurate seat totals by party and region. In particular, they quite accurately and convincingly predict the Conservative majority government, giving them 160 seats out of the 308 national total.

\section{Effects of Small Systematic Shifts.}

The previous section illustrates that our preferred model (i.e., model (2) with the overperforming effect) does correctly predict the Conservative majority government, giving them 160 seats which is comfortably over the 155 needed for a majority and not too far from the 166 seats they actually won.

However, any such forecasts necessarily contain some uncertainty. In this section, we consider the extent to which small systematic shifts in voter behaviour will affect the resulting seat counts.

As a first question, we suppose that the over-performing effect is not incorporated into the model, and ask how much systematic voter shift would be required to still predict a Conservative majority. The results are as follows:

\begin{tabular}{|c|c|c|c|c|c|}
\hline & Con & Lib & NDP & Bloc & Grn \\
\hline Shift: & 0 & 0 & 0 & 0 & 0 \\
Seats: & 148 & 37 & 111 & 12 & 0 \\
\hline Shift: & $1.35 \%$ & $-1.35 \%$ & 0 & 0 & 0 \\
Seats: & 156 & 28 & 112 & 12 & 0 \\
\hline Shift: & $1.45 \%$ & 0 & $-1.45 \%$ & 0 & 0 \\
Seats: & 155 & 36 & 104 & 13 & 0 \\
\hline Shift: & $1.5 \%$ & $-0.75 \%$ & $-0.75 \%$ & 0 & 0 \\
Seats: & 156 & 32 & 107 & 13 & 0 \\
\hline
\end{tabular}

Table 7: Projected seat counts by party for the 2011 election, using the model (2) but without the over-performing effect from Table 3 , in the presence of small systematic national shifts of voters between parties. 
We see that if the Conservatives were able to systematically increase their nominal poll average support by just $1.35 \%$ at the expense of the Liberals, or just $1.45 \%$ at the expense of the NDP, or just $1.5 \%$ equally from each of the Liberals and NDP, then this would be sufficient to propel them to a majority. We conclude from this that, even without the overperforming effect of Table 3, the Conservative majority was possible under very small voter shifts and thus should certainly not have been ruled out to the extent that it was.

We next consider the case where the over-performing effect $i s$ incorporated into the model, and ask how much systematic voter shift would be required to not predict a Conservative majority. The results are as follows:

\begin{tabular}{|c|c|c|c|c|c|}
\hline & Con & Lib & NDP & Bloc & Grn \\
\hline Shift: & 0 & 0 & 0 & 0 & 0 \\
Seats: & 160 & 33 & 103 & 12 & 0 \\
\hline Shift: & $-1.1 \%$ & $1.1 \%$ & 0 & 0 & 0 \\
Seats: & 154 & 39 & 102 & 13 & 0 \\
\hline Shift: & $-0.9 \%$ & 0 & $0.9 \%$ & 0 & 0 \\
Seats: & 154 & 36 & 106 & 12 & 0 \\
\hline Shift: & $-1.0 \%$ & $0.5 \%$ & $0.5 \%$ & 0 & 0 \\
Seats: & 154 & 36 & 105 & 13 & 0 \\
\hline
\end{tabular}

Table 8: Projected seat counts by party for the 2011 election, using the model (2) together with the over-performing effect from Table 3, in the presence of small systematic national shifts of voters between parties.

We see that starting with the over-performing effect from Table 3, if the Conservatives systematically lost just $1.1 \%$ of voters to the Liberals, or just $0.9 \%$ of voters to the NDP, or just $1.0 \%$ of voters equally to the Liberals and NDP, then this would be sufficient to deny them a majority. We conclude from this that, although the over-performing effect of Table 3 does indeed predict a Conservative majority, this majority is rather tenuous and could evaporate under very small voter shifts.

Finally, we note that at least one observer [9] claimed that votes shifting from the Liberals directly to the NDP would give more seats to the Conservatives (even though the Conservative vote would remain unchanged), due to the nature of riding-by-riding vote splits especially in Ontario. We examine this by starting with our preferred model (i.e., model (2) with the over-performing effect). We then assume a systematic national shift of some percentage of voters from the Liberals directly to the NDP, and compute the resulting predicted number of Conservative seats. Our results are as follows: 


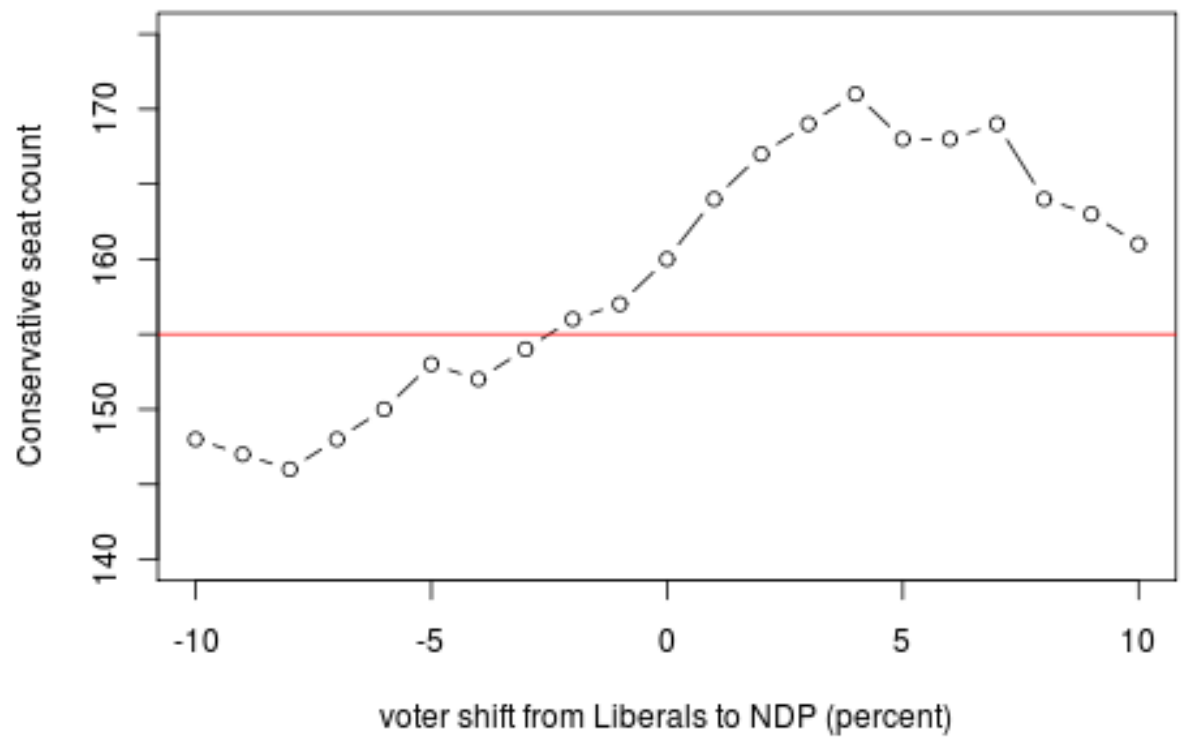

Figure 2: Predicted number of Conservative seats starting with our preferred model (i.e., model (2) with the over-performing effect) and then assuming a systematic national shift of some percentage of voters from the Liberals directly to the NDP.

We see from this graph that a voter shift from the Liberals directly to the NDP does indeed help the Conservatives fairly consistently over quite a wide range of shifts (i.e., from $-8 \%$ up to $+4 \%)$. Within this range, the larger the shift, the larger the Conservative majority. By contrast, if the shift is $-3 \%$ or less (i.e., if at least $3 \%$ of voters move from the NDP directly to the Liberals), this this would deny the Conservatives their majority of 155 seats. This is thus consistent with early predictions [9] that vote shifts from the Liberals directly to the NDP would give more seats to the Conservatives.

To determine whether such voter shifts (of a few percent of voters) are likely or unlikely, we need to assess the uncertainty of our predicted voting popularity $p$ of each party.

Now, one source of uncertainty for $p$ is the sampling error of public opinion polls, i.e. the "margin of error". Here $p$ is estimated by taking the average of $n$ independent Bernoulli $(p)$ responses, so it has variance $p(1-p) / n$ and standard deviation $\sqrt{p(1-p) / n}$ which is upperbounded by $1 / 2 \sqrt{n}$. (This leads to the pollsters' usual "margin of error", i.e. $95 \%$ confidence interval half-width, equal to $1.96 / 2 \sqrt{n}=98 \% / \sqrt{n}$; see e.g. [33].) In averaging the nine pre-election polls in Table 1 above, we obtain an effective sample size of $n=18707$. (Of course, the polls in Table 1 use different sampling methods and cannot necessarily be combined perfectly, but summing their sample sizes is still a reasonable way of esti- 
mating their combined accuracy.) This implies a sampling standard error for $p$ which is $\leq 1 / 2 \sqrt{n} \doteq 0.003656 \doteq 0.37 \%$. This figure is considerably smaller than the shifts required above. This suggests that on the basis of sampling error alone, such shifts are quite unlikely, and our general conclusion (that the Conservative majority is predictable provided the over-performing effects are taken into account) is fairly robust. (Of course, it is true that the standard deviations are larger for regional subpopulations, e.g. for Ontario alone the standard deviation upper bound is about $0.59 \%$, but this is still much smaller than the above shift amounts, and anyway the sampling errors for different regions are independent and thus would not tend to reinforce each other.)

On the other hand, opinion polls have many other sources of error besides sampling error (see e.g. [33, 34]), including party-dependent availability and response rates, non-voters, lastminute changes of opinion, etc. These errors are very hard to quantify precisely. However past election polls and results give some guidance. For example, it is well known (see e.g. $[37,38,6,34])$ that in the 2004 Canadian election, approximately $5 \%$ of the electorate made a last-minute shift from the NDP to the Liberals in an effort to prevent the Conservatives from winning the election. ("The Liberal surge was literally overnight", lamented senior

NDP advisor Jamey Heath.) This suggests that it is not unreasonable to suppose that final vote tallies might be off by 1-3 percent from the best pre-election estimates, even after party over-performing effects are taken into account. If so, then the above voter shift values are not unreasonable, and we conclude that a Conservative majority was not guaranteed even with the over-performing effect, nor was it precluded without the over-performing effect, but rather usual last-minute voter shifts could have created or denied the majority in any case.

\section{Conclusion.}

We have considered a simple seat projection method for Canadian elections, consisting of beginning in each riding with the previous election results, and then modifying them as in (2) (or (1)) based on the latest regional pre-election poll averages together with each party's estimated over-performing effect.

This simple model provides seat projections which are quite close to the actual 2011 election results (Table 6). In particular, they correctly predict that the Conservatives will win a majority of the 308 seats available. In this sense, we claim that the Conservative majority was indeed predictable, contrary to the general pre-election consensus of the pollsters and media (see Section 3). 
We further showed that small systematic voter shifts (of about $1 \%$ of the population) would have been sufficient to reduce the Conservatives to a minority (or, contrariwise, to give them a majority even without taking the parties' over-performance effects into account). Since such small last-minute voter shifts are well within historic levels, this suggests that while the Conservative majority should have been predicted as the most likely outcome, it was still far from certain.

It is thus our opinion that pre-election seat predictions and media reports should have realised that a Conservative majority was the most likely outcome, although not certain. Seen in this light, the near-unanimous claims of pre-election forecasters that a Conservative majority was extremely unlikely, were unjustified and unfortunate (and may even have influenced some voters to vote differently without any "fear" of a Conservative majority). It is to be hoped that more accurate seat forecasts will be provided in future elections.

Acknowledgements. We thank Margaret Fulford for media research assistance. 


\section{References}

[1] Abacus Data public opinion poll, May 1, 2011, "Tories headed for win; NDP a strong second". Available at:

http://abacusdata.ca/wp-content/uploads/2011/05/Ballot-May-1-2011.pdf

[2] Angus-Reid public opinion poll, April 27, 2011. Available at:

http://www.angus-reid.com/polls/43882/tories-lead-in-canada-ndp-firmly-in-secondplace-due-to-quebec-strength/

[3] Angus-Reid public opinion poll, April 30, 2011, "Conservatives and NDP gain in Canada, as Liberals fall below $20 \%$ mark". Available at: http://www.angusreid.com/wp-content/uploads/2011/04/2011.04.30_FedPoli_CAN.pdf

[4] R. Benzie, Toronto Star, April 29, 2011, "Exclusive: Majority out of reach, Tories say". Available at: http://www.thestar.com/news/canada/politics/article/982356exclusive-majority-out-of-reach-tories-say

[5] R. Benzie, Toronto Star, April 30, 2011, "Harper ducks questions on Governor General and coalition". Available at:

http://www.thestar.com/news/canada/politics/article/983414-harper-ducksquestions-on-governor-general-and-coalition

[6] Calgary Grit blog post, "The Perils of Strategic Voting". Available at: http://calgarygrit.blogspot.com/2004/06/perils-of-strategic-voting-without.html

[7] CBC News news item, April 7, 2011, "Ajax-Pickering riding key election battleground". Available at: http://www.cbc.ca/news/canada/toronto/story/2011/04/06/toronto-ajaxpickering347.html

[8] Compas public opinion poll, May 1, 2011, "Wild Card - Possibly the most bizarre, unstable, upside-down election since Confederation". Available at: http://www.compas.ca/data/110501-FedElectionPoll-EPCB.pdf

[9] C. Cosh (Maclean's magazine national columnist), blog post of May 1, 2011. Available at: http://www2.macleans.ca/2011/05/01/election-forecast-dance-on-a-razors-edge/

[10] A. Coyne (Maclean's magazine national columnist), blog post of April 25, 2011. Available at: http://www2.macleans.ca/2011/04/25/fascist-takeover-commalition-consensus-at-last/ 
[11] M. De Souza, National Post, April 29, 2011, "Tales from the trail". Available at: http://www.nationalpost.com/todays-paper/Tales+from+trail/4694417/story.html

[12] Ekos public opinion poll, May 1, 2011, "Our final words and a few more numbers". Available at:

http://www.ekospolitics.com/wp-content/uploads/final_seat_projection_may_1.pdf

[13] Elections Canada web site, Fortieth General Election 2008, Table 12: List of candidates by electoral district and individual results. Available at: http://www.elections.ca/scripts/OVR2008/31/data/table_tableau12.csv

[14] Forum Research public opinion poll, May 1, 2011, "NDP Surge Stalls, Tories Near Majority". Available at: http://www.einnews.com/pr-news/399269-ndp-surge-stalls-tories-near-majority-

[15] S. Freeman, Winnipeg Free Press, May 1, 2011, "Traders jolted awake by election uncertainty; could see loonie, stock volatility". Available at: http://www.winnipegfreepress.com/business/breakingnews/traders-jolted-awake-byelection-uncertainty-could-see-loonie-stock-volatility-121048444.html

[16] D. Frum, National Post, April 30, 2011, "The day after the election". Available at: http://www.nationalpost.com/opinion/columnists/after+election/4701816/story.html

[17] E. Grenier (2011), ThreeHundredEight.com web site and blog.

[18] T. Harper, Toronto Star, April 28, 2011, "Winds of change buffet Harper". Available at: http://www.thestar.com/news/canada/politics/article/982316-tim-harper-windsof-change-buffet-harper

[19] K. Harris, National Post, May 1, 2011, "Conservative-NDP gap narrows to three points in dwindling hours of campaign". Available at: http://news.nationalpost.com/2011/05/01/conservative-ndp-gap-narrows-to-threepoints-in-dwindling-hours-of-campaign/

[20] Harris-Decima public opinion poll, May 1, 2011, "Conservatives lead by six". Available at:

http://www.harrisdecima.ca/sites/default/files/releases/2011/05/01/hd-2011-05-01 -en1163.pdf and also at: http://www.decima.com/news/releases/201105/1163-conservatives-lead-six 
[21] A. Heard (2011), Election Opinion Polls web site. Available at: http://www.sfu.ca/ aheard/elections/polls.html

[22] A. Heard (2011), 2011 Canadian Election Results. Available at: http://www.sfu.ca/ aheard/elections/results.html

[23] Ipsos-Reid public opinion poll, April 29, 2011, "Conservatives (38\%) lead charging NDP (33\%), decimated Liberals (18\%) as Bloc (7\%) falter and Green (4\%) trail far behind". Available at: http://www.ipsos-na.com/news-polls/pressrelease.aspx?id=5224

[24] J. Ivison, National Post, April 29, 2011, "Harper's Words Of Warning". Available at: http://www.nationalpost.com/Harper+Words+Warning/4696722/story.html

[25] Leger Marketing public opinion poll, April 30, 2011, "National Poll, Federal Election 2011'. Available at: http://www.legermarketing.com/documents/POL/114301ENG.pdf

[26] D. Ljunggren, Reuters news agency, May 1, 2011, "Canada set for election, result too tight to call". Available at: http://www.reuters.com/article/2011/05/01/us-politics-idUSTRE73Q44720110501

[27] R. Mickleburgh, Globe and Mail, April 30, 2011, "Effects of NDP surge rumbling through B.C.". Available at: http://www.theglobeandmail.com/news/national/britishcolumbia/bc-politics/effects-of-ndp-surge-rumbling-through-bc/article2004872/

[28] D. Minicucci, Global News, May 1, 2011, "Experts suggest Tory minority, coalition as possible election outcomes". Available at:

http://www.globaltoronto.com/decisioncanada/Experts+suggest+Tory+minority+coalition+possible+election+outcomes/4706548/story.html

[29] C. Mitchell, Winnipeg Free Press, April 30, 2011, "The beauty and the beast of democracy". Available at:

http://www.winnipegfreepress.com/opinion/columnists/the-beauty-and-the-beast-ofdemocracy-121017044.html

[30] Nanos public opinion poll, May 1, 2011, "Tories ahead on eve of Election Day". Available at: http://www.nanosresearch.com/election2011/20110501-BallotE.pdf 
[31] T. Naumetz, The Hill Times Online, May 1, 2011, "NDP, Tories in virtual dead heat, either party could form minority government, says Forum Research poll". Available at: http://hilltimes.com/dailyupdate/view/ndp_tories_in_virtual_dead_heat_either_party_could_form_minority_government_says_forum_research_poll_05-01-2011

[32] R. Rolke, Vernon Morning Star, May 1, 2011, "Mayes confident, NDP bracing for historic election". Available at: http://www.bclocalnews.com/okanagan_similkameen/vernonmorningstar/news/120995434.html

[33] J.S. Rosenthal (2003), "Margins of error in opinion polls". Available at: http://probability.ca/jeff/writing/pollerror.html

[34] J.S. Rosenthal (2005), "Struck by Lightning: The Curious World of Probabilities". HarperCollins Canada.

[35] J.S. Rosenthal (2011), Election prediction software, "elecpred.c". Available at: http://probability.ca/election/

[36] J. Taber, Globe and Mail, June 14, 2011, "Harper's majority-strength team puts media critics in its crosshairs". Available at: http://www.theglobeandmail.com/news/politics/ottawa-notebook/harpers-majoritystrength-team-puts-media-critics-in-its-crosshairs/article2060321/

[37] P. Wells, Maclean's magazine, July 12, 2004, "The Inside Story of Canada's Nastiest Campaign".

[38] P. Wells, The Canadian Encyclopedia (2004), "Martin Wins Nasty Campaign". Available at:

http://www.thecanadianencyclopedia.com/index.cfm?PgNm=TCE\&Params=M1ARTM0012622

[39] Wikipedia, Opinion Polling in the Canadian Federal Election, 2011. Available at: http://en.wikipedia.org/wiki/Opinion_polling_in_the_Canadian_federal_election,_2011 